\title{
Chile 2015: Falla POlítica, Desconfianza Y REFORMA
}

Chile 2015: Political Failure, Distrust and Reform

\section{RICARDO GAMBOA}

Universidad de Chile

\section{CAROLINA SEGOVIA}

Universidad Diego Portales

\section{RESUMEN}

Este artículo describe y analiza el proceso político del segundo año del gobierno de Michelle Bachelet. El 2015 se caracterizó por el estallido de casos de corrupción política y económica, un déficit mayor en la conducción política por parte del gobierno y las coaliciones de partidos, y el desplome de los índices de confianza en los principales actores. No obstante, hubo importantes avances legislativos, que modifican la institucionalidad política y que reconocen derechos sociales y políticos.

Palabras clave: Chile, corrupción, desconfianza, reforma política.

\begin{abstract}
This article describes and analyzes the political process during Michelle Bachelet's second year in government. As it will be shown, the year 2015 was marked by the emergence of important cases of political and economic corruption, deep deficits in the political leadership of government and political coalitions, and a pronounced decline of trust in main political actors. Nevertheless, important legislative changes occurred that modified political institutions and improved social and political rights.
\end{abstract}

Key words: Chile, corruption, distrust, political reform. 


\section{INTRODUCCIÓN}

El 2015 fue muy difícil para el sistema político chileno. Distintos procesos judiciales afectaron profundamente a la presidencia, a los principales partidos políticos y al empresariado. La consecuencia fue el desplome de la confianza pública en ellos. En este marco, el sistema decisorio evidenció serios problemas. Por un lado, el gobierno mostró falta de liderazgo en la conducción política, carencia de cohesión interna y serias dificultades para definir su agenda y el contenido de sus propuestas de reformas. La coalición de partidos oficialista, la Nueva Mayoría ${ }^{1}(\mathrm{NM})$, exhibió también profundos problemas de funcionamiento. No solo emergieron fisuras entre sus partidos respecto de los contenidos de las reformas que proponía el gobierno, sino que también evidenciaron problemas de cohesión interna. Por el otro, los partidos de oposición carecieron también de cohesión y fortaleza, sea por efectos de los casos judiciales o problemas de funcionamiento interno. Los empresarios, a su vez, fueron muy golpeados por los escándalos judiciales de financiamiento y de colusión de precios, mientras mantuvieron una actitud muy crítica frente al gobierno y sus reformas. Lo anterior, en consecuencia, configuró un escenario marcado por un sistema político sumido en una profunda crisis de confianza, carente de conducción gubernamental y donde los demás actores no mostraban la disposición, cohesión y voluntad de acción colectiva para hacer funcionar el sistema adecuadamente. Es decir, el sistema político demostró tener una "falla" mayor.

Con todo, en 2015 también hubo cambios positivos. Los principales se vinculan a reformas institucionales a las condiciones de competencia política. A estas se suman la concreción del beneficio de gratuidad universitaria para el 50\% de la población más vulnerable y el establecimiento del Acuerdo de Unión Civil, ambos pasos importantes en el fortalecimiento de los derechos de las personas.

\section{Los comienzos del segundo gobierno de Bachelet (2014)}

Michelle Bachelet y la NM inauguraron su gobierno en marzo de 2014. El escenario inicial era auspicioso, ya que Bachelet había sido elegida con un $62,2 \%$ de votos en la segunda vuelta electoral de 2013 y la NM obtuvo amplia mayoría en ambas Cámaras del Parlamento (Castiglioni, 2014). Esto permitiría, en principio, avanzar con fluidez en la ambiciosa agenda reformadora del nuevo gobierno. En este escenario, el gobierno priorizó avanzar en la reforma educacional, desarrollando una nueva institucionalidad en materias de: inclusión escolar, sistema de financiamiento de la educación escolar y prohibición del lucro y regulación universitaria. A su vez, para financiarla impulsó una profunda reforma tributaria. Por otra parte, se pospuso -para 2015- la definición del mecanismo de reforma constitucional (prioridad principal del programa de gobierno), $\mathrm{y}$ se promovió una reforma electoral para terminar con el sistema binominal para la elección de parlamentarios vigente desde 1989 (ver abajo). Si nos detenemos solo en el avance de

La Nueva Mayoría está integrada por siete partidos: Partido Demócrata Cristiano (PDC), Partido por la Democracia (PPD), Partido Socialista (PS), Partido Radical Social-Demócrata (PRSD), Partido Comunista (PC), Izquierda Ciudadana (IC) y Movimiento Amplio Social (MAS). 
las reformas, el resultado fue bueno para el gobierno. Por un lado, y pese a dificultades y críticas, logró la aprobación de sus principales reformas en materia educacional (leyes 20.800 y 20.845, promulgadas en 2015), así como la reforma tributaria (Ley N ${ }^{\circ} 20.780$ ). Igualmente, cerró un acuerdo por la reforma electoral, la cual fue promulgada en mayo de 2015 (Ley $\mathrm{N}^{\mathrm{o}}$ 20.840).

Sin embargo, en 2014 emergieron también problemas mayores para el sistema político. Primero, la discusión educacional estuvo cruzada por importantes discrepancias no solo entre gobierno y oposición, sino al interior de la NM. Estas fisuras dentro de la NM ponían dudas acerca del futuro de la agenda reformista. En el caso de la reforma tributaria, ella tuvo como efecto un deterioro profundo de las relaciones con el sector empresarial, y el ministro de Hacienda (Alberto Arenas) terminó el año muy debilitado.

Segundo, estalló uno de los principales casos judiciales de financiamiento ilegal de la política, el denominado caso PENTA. ${ }^{2}$ Este afectó fuertemente al principal partido de oposición, la Unión Demócrata Independiente (UDI), ${ }^{3}$ además de otros actores, como el ex ministro de Hacienda de Bachelet y eventual candidato presidencial, Andrés Velasco. Más allá de lo que significó para partidos y políticos particulares, esto derivó en un deterioro mayor de las relaciones gobierno-oposición. Asimismo, era previsible que surgieran otros casos de financiamiento ilegal de la política que afectarían a miembros de la NM.

Tercero, la situación económica empeoraba. Las perspectivas de crecimiento eran débiles y por tanto la continuidad reformista enfrentaría un problema de financiamiento. Por último, y no menor, la popularidad de Bachelet comenzó a deteriorarse sistemáticamente, bajando de 54\% al inicio de su gobierno al 40\% en diciembre de 2014 (ver Figura 1).

\section{TEMAS SALIENTES EN LA REALIDAD NACIONAL Y SU IMPACTO POLÍTICO}

\section{Coyuntura Política y Social}

Los problemas que se incubaron en 2014 se profundizaron en 2015, año marcado por una desconfianza profunda y deterioro sustantivo de la imagen pública de los principales actores políticos, y la incapacidad del sistema para responder adecuadamente a este desafío.

Durante el año, la popularidad presidencial se derrumbó progresivamente, cayendo al 24\% en diciembre de 2015 (Figura 1). Al mismo tiempo, el apoyo a sus reformas se mantuvo bajo: el apoyo a la reforma educacional no alcanzó el $50 \%$ durante todo el año. En el caso de la reforma laboral, la caída en el apoyo fue sostenida: de 53\% (en enero) a 35\% (en diciembre) (Adimark, 2015). Asimismo, las encuestas mostraban una baja

2 PENTA es un grupo económico presente en distintos sectores (financiero, salud, inmobiliario), liderado por dos conocidos empresarios (Carlos Délano y Carlos Lavín) cercanos a la UDI.

3 De hecho, uno de sus líderes principales, Jovino Novoa, fue declarado culpable de cometer delitos tributarios relacionados con el caso. 
Figura 1. Aprobación presidencial, 2014-2015

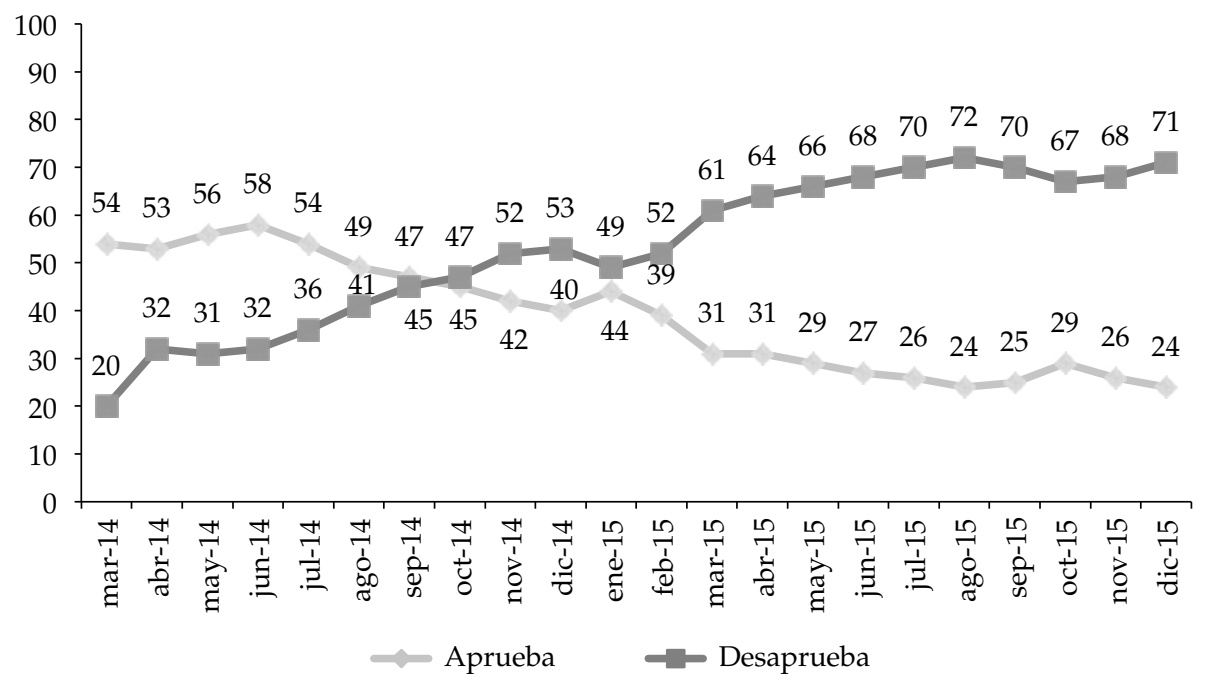

Fuente: Adimark, Encuesta Evaluación Gestión del Gobierno. Diciembre 2015.

aprobación a la gestión del gobierno en las áreas consideradas como prioritarias por los ciudadanos. De acuerdo a datos de la encuesta CEP de noviembre de 2015, los chilenos califican la gestión del gobierno en educación con nota 3,3 (escala 1 a 7); en salud con un 2,9; y en delincuencia con un 2,6.

Pero no fue solo Bachelet, sino también los actores más relevantes del sistema, como partidos, Congreso y empresarios, los que vieron deteriorada su imagen pública en 2015. Este deterioro, sin embargo, no puede ser atribuido solo a la coyuntura de 2015, sino también a tendencias de largo plazo que han sido evidentes en el país. De acuerdo a datos de la Encuesta CEP, por ejemplo, entre 2011 y 2015 la confianza en las principales instituciones del país tuvo caídas importantes: en los partidos políticos de $7 \%$ a $3 \%$, en el Congreso de $13 \%$ a 6\%, en los Tribunales de 13\% a 7\%, en el Ministerio Público de $17 \%$ a $11 \%$, y en las empresas de $18 \%$ a $12 \%$. La evaluación del funcionamiento de la democracia también se resintió: en noviembre de 2015, apenas un 10\% señalaba que la democracia en Chile funciona bien o muy bien. En resumen, 2015 exhibió un debilitamiento significativo de la confianza en las principales instituciones de la democracia.

¿Por qué se llegó a esto? Acá los elementos principales.

Primero, porque el gobierno, y en particular Bachelet, sufrieron un debilitamiento progresivo en 2015. Central a este respecto fue la emergencia del "Caso Caval" en febrero de 2015. ${ }^{4}$ Este involucraba directamente al hijo de Bachelet (Sebastián Dávalos) y a su 
nuera (Natalia Compagnon), en un negocio de compra de un terreno en la comuna de Machalí (Sexta Región) con ocasión del cual se habrían cometido actos ilegales, como sobornos y tráfico de influencias. Si bien Dávalos, que a la fecha era director de Área Sociocultural de la Presidencia, renunció a su cargo una semana después, la respuesta pareció insuficiente para gran parte de los medios y de la opinión pública, ya que nunca hubo admisión de algún error o culpa y el negocio permaneció a firme.

Segundo, como se preveía emergió un segundo escándalo de financiamiento ilegal de la política, el llamado caso Soquimich (SQM). Este se refiere al descubrimiento de distintos pagos por parte de esta empresa, que es la mayor minera no metálica del mundo y era presidida por el ex yerno de Augusto Pinochet (Julio Ponce), a políticos de distintos sectores desde al menos el año 2009.5 A diferencia del caso PENTA, aquí aparecen involucrados políticos de los partidos más importantes de la NM, más el ex candidato presidencial Marco Enríquez-Ominami, el ex presidente Sebastián Piñera, la UDI, y otros. El caso "salpicó" también a Bachelet, ya que SQM habría pagado a una empresa conformada por colaboradores cercanos (como su ministro del Interior, Rodrigo Peñailillo), los cuales habrían ido a financiar su campaña electoral.

A lo anterior, se agregaron otras investigaciones sobre eventual financiamiento político ilegal, que involucran a otros actores empresariales como los Grupos Angelini y Said, Aguas Andinas, Ripley, Endesa y el Banco BCI. Como consecuencia de esto, muchos políticos y empresarios de diversos sectores (con algunas excepciones) han debido comparecer repetidamente ante las autoridades judiciales. De hecho, varios de ellos han sido ya formalizados por delitos específicos (también Compagnon). Estas son aún investigaciones en curso. Por tanto no se conoce si habrá más formalizaciones y condenas, y en definitiva cuáles serán sus consecuencias finales.

Las denuncias de corrupción llegaron también al Ejército, al descubrirse un millonario fraude en el que estarían involucrados funcionarios de distintos rangos. Este se conoce como "Milicogate", y es también una investigación en curso. ${ }^{6}$

Los primeros meses de 2015 fueron entonces muy difíciles. Bachelet reaccionó anunciando, en una entrevista televisiva con un importante animador y sin previa consulta a la NM, que realizaría un cambio de gabinete. ${ }^{7}$ En lo principal, este cambio significó la salida de Peñailillo (PPD), muy debilitado por el caso SQM, del Ministerio del Interior y Arenas (PS) del Ministerio de Hacienda (primera vez que un ministro de Hacienda sale por una situación de debilidad política desde 1990). Ellos fueron reemplazados por el político del PDC Jorge Burgos y el destacado economista Rodrigo Valdés (PPD), respectivamente. Poco después, luego del fracaso de la designación de Jorge Insunza, Nicolás Eyzaguirre

5 http://ciperchile.cl/2015/09/07/platas-negras-de-sqm-el-pulpo-que-puso-sus-tentaculos-en-todos-lossectores-politicos/.

6 http://www.theclinic.cl/2015/10/17/la-serie-completa-del-milicogate-el-multimillonario-robo-del-fondoreservado-del-cobre/.

7 http://www.latercera.com/noticia/politica/2015/05/674-628561-9-bachelet-pide-renuncia-a-todos-susministros-ydisena-profundo-cambio-de-gabinete.shtml. 
(hasta entonces ministro de Educación) asumió el Ministerio Secretaría General de la Presidencia (SEGPRES), encargado de definir y liderar la agenda legislativa del gobierno. ${ }^{8}$

Los cambios ministeriales no tuvieron el efecto positivo esperado. Esto por varias razones. El gobierno siguió mostrándose débil y errático en la toma de decisiones, además de carente del liderazgo necesario para conducir el proceso político y llevar adelante una agenda reformista con un contenido definido. ${ }^{9}$ En ese contexto, ha sido evidente que Burgos (Ministro del Interior) no cuenta con la confianza de Bachelet para constituirse como un efectivo líder del gabinete. De hecho, ha sido muy notoria su exclusión de algunas decisiones, que incluso se vinculan con su cargo. ${ }^{10}$

Luego, los partidos de la NM, muy golpeados por la crisis de financiamiento ilegal y evidenciando signos fuertes de debilidad y falta de cohesión interna, tampoco contribuían a resolver el problema. A falta de liderazgo presidencial, emergieron con fuerza las críticas de parte de parlamentarios del PDC respecto de algunas propuestas del gobierno. ${ }^{11}$ Los restantes partidos de la coalición tampoco conformaron un bloque con una postura única y clara sobre cuál debía ser el contenido específico de los cambios.

En la oposición, reunida ahora en el conglomerado "Chile Vamos", el escenario tampoco fue el mejor. La crisis interna de la UDI (sumado a su rechazo a la agenda del gobierno) y la falta de cohesión de Renovación Nacional (RN) los hizo actores más bien débiles, que actuaban más por reacción, y sin la capacidad y disposición necesarias para cumplir su rol en buena forma.

La coyuntura social, por su parte, estuvo marcada por conflictos relevantes en algunos sectores. Uno principal fue el liderado por el gremio de los profesores, que en respuesta a un proyecto de Estatuto Docente (cuerpo legal que regula a los profesionales de la educación), paralizaron buena parte de la educación escolar por 57 días. ${ }^{12}$ El segundo, fue el conflicto entre el gobierno y los funcionarios del Registro Civil. En rechazo a demandas relacionadas con beneficios pecuniarios (reajuste de sueldo y bonos), los funcionarios realizaron un paro de actividades que se prolongó por 39 días, lo que causó gran molestia en la ciudadanía, que se veía imposibilitada de obtener documentación necesaria (cédula de identidad, pasaportes) para distintos fines ${ }^{13}$.

El tercero, de menor duración pero de fuerte impacto político, fue la movilización organizada por la Confederación Nacional de Transportistas de Carga (CNTC), en demanda por mayor

8 El detalle de los cambios realizados se encuentran en la sección IV de este artículo.

9 Esto fue muy visible en 2015. El mejor ejemplo fue lo ocurrido respecto a la definición de los requisitos que debían cumplir los estudiantes para obtener el beneficio de gratuidad universitaria, la cual cambió al menos cinco veces. Asimismo, durante largo tiempo han estado vacantes puestos importantes dentro del Ejecutivo ( 2 subsecretarías al menos 2 meses), como también dentro de la administración estatal (ver caso de Contralor General de la República).

10 http://www.quepasa.cl/articulo/politica/2015/12/bachelet-margina-a-burgos-de-sorpresivo-viaje-a-laaraucania.shtml/.

11 http://www.latercera.com/noticia/nacional/2015/09/680-646470-9-ignacio-walker-no-hay-razon-para-nobuscar-un-consenso-en-la-reforma-educacional.shtml.

12 http://www.latercera.com/noticia/nacional/2015/07/680-640401-9-asamblea-de-profesores-decide-ahoracontinuidad-del-paro.shtml.

13 http://www.t13.cl/noticia/nacional/se-termina-paro-del-registro-civil-funcionarios-llegan-acuerdo-gobierno. 
protección ante múltiples ataques a camiones de transporte ocurridos en la zona sur del país (Araucanía) en el marco del denominado "Conflicto Mapuche". Los camioneros buscaban hacer desfilar frente a La Moneda (el Palacio de Gobierno) 13 maquinarias que habían sido quemadas en el último tiempo, y así visibilizar su condición de víctimas. El gobierno rechazó esa petición y propuso alternativas que los camioneros no aceptaron, lo que derivó en un bloqueo total del acceso terrestre a Santiago por el sector sur por más de 10 horas (liderado por la CNTC), provocando grandes problemas. ${ }^{14}$ En definitiva el gobierno cedió, permitiendo la entrada de camiones a Santiago y recibiendo el ministro Burgos a los dirigentes. ${ }^{15}$ Este episodio reflejó la debilidad del gobierno para defender con eficacia su posición en relación a los distintos conflictos sociales.

Por otro lado, llama la atención el menor protagonismo del movimiento estudiantil. Si bien fue activo en la prensa defendiendo sus postulados generales en torno a la reforma educacional, y manteniendo una posición crítica frente al actuar del gobierno, no desarrolló una actividad de movilización importante, como el 2011 (Segovia y Gamboa, 2012).

Finalmente, cabe mencionar que durante 2015 el gobierno debió enfrentar al menos 5 eventos importantes de desastres naturales: la erupción del volcán Villarrica y los aluviones en la zona norte del país (marzo), la erupción del volcán Calbuco en abril, fuertes temporales en la zona norte y centro del país en agosto, y el terremoto y tsunami de la zona centro-norte en septiembre. Todos estos tuvieron consecuencias importantes para la población afectada, obligando al gobierno a movilizar recursos extraordinarios para la recuperación de las zonas. La noticia feliz, que no obstante no tuvo ningún efecto político, fue la obtención de la Copa América de fútbol.

\section{Coyuntura económica}

Durante 2015 la economía mantuvo, en general, las características observadas en 2014 (Figura 2). Se registró un crecimiento en torno al 2\%, lo que se asocia a la evolución de los precios de la minería, a la situación económica internacional, y a las bajas expectativas que las reformas del gobierno generan en el empresariado (Corbo, 2016). Destaca particularmente la caída del precio del cobre hacia fines de 2015 (de 2,9 dólares / libra en diciembre de 2014 a 2,1 en diciembre del 2015, lo que representa una caída de 27,6\%). ${ }^{16}$ El empleo se mantuvo estable, con una tasa de desocupación de 5,8\% para el trimestre móvil de octubre-diciembre (INE, 2016b). La inflación alcanzó una variación de 4,4\% (INE, 2016a), levemente superior a las expectativas iniciales (Corbo, 2016). Por último, la tasa de inversión de 2015 se proyecta en torno al 22\% del Producto Interno Bruto (PIB) y sería una de las más bajas de esta década.

14 http://www.emol.com/noticias/Nacional/2015/08/27/746938/Carabineros-detiene-a-caravana-decamioneros-en-Angostura-y-dirigentes-amenazan-con-paro-nacional.html.

15 http://www.elmostrador.cl/noticias/pais/2015/08/27/burgos-destraba-el-conflicto-con-los-camioneros-yacuerda-que-algunos-lleguen-a-la-moneda/.

16 http://si3.bcentral.cl/Siete/secure/cuadros/home.aspx. 
Figura 2. Principales indicadores económicos, 2014-2015

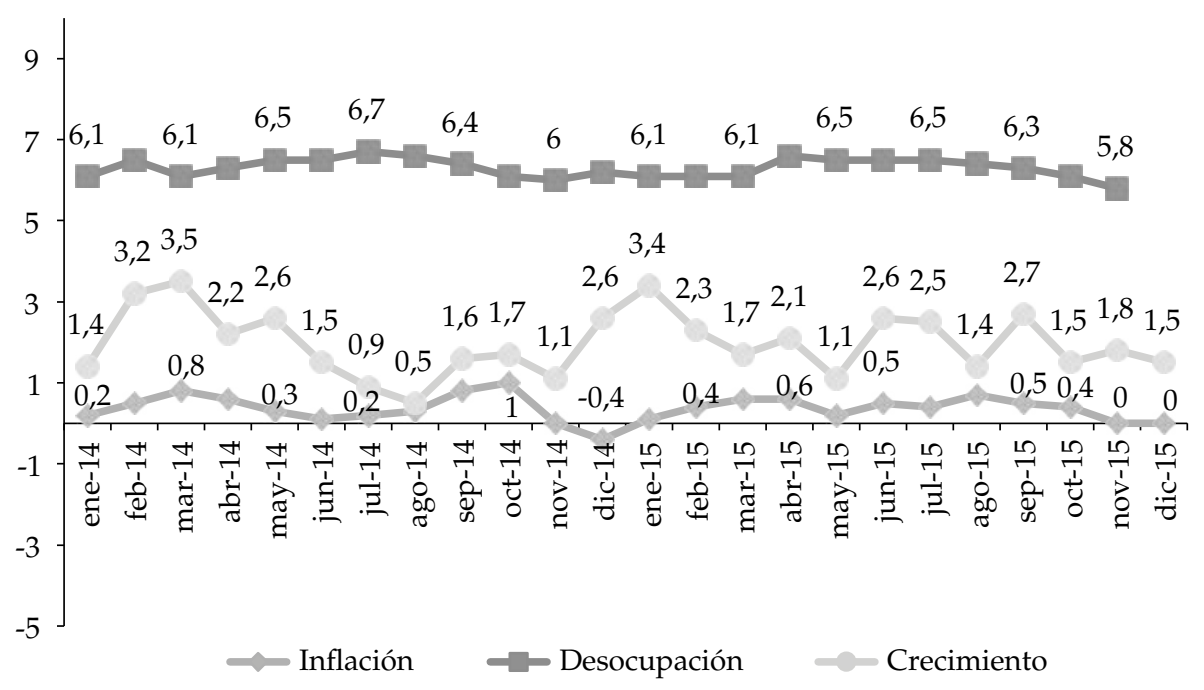

Fuente: INE y Banco Central.

Consecuentemente, para 2016 las expectativas económicas no son buenas. De hecho, las proyecciones de crecimiento del PIB han sido recurrentemente corregidas a la baja, fluctuando ahora entre 1,5 y 2,5\%. ${ }^{17}$ Dado este escenario, el ministro Valdés tiene el difícil desafío de generar las condiciones para mejorar el clima económico y recuperar la confianza empresarial. En ese sentido, un primer paso legislativo fue la presentación de un proyecto de ley de "reforma a la reforma tributaria" (Boletín 10442-05),18 y que fue aprobado en enero de 2016.

Durante 2015 fue central también la discusión de una reforma laboral, muy criticada por el empresariado. Este proyecto plantea modificar el Código del Trabajo en distintas materias. Especialmente controvertidas han sido las propuestas sobre titularidad sindical en la negociación colectiva, reemplazo de trabajadores en huelga y las relativas al acceso a beneficios de los contratos colectivos. Mientras sus defensores ven en ellas mecanismos adecuados (aun cuando no suficientes) para el fortalecimiento de los derechos de los trabajadores, ${ }^{19}$ los empresarios critican el que ella tendría efectos negativos sobre el empleo, da un poder excesivo a los sindicatos y atenta contra la libertad de los trabajadores. ${ }^{20}$

17 http://www.elmercurio.com/Inversiones/Noticias/Fondos-Mutuos/2015/11/27/Proyecciones-economicas-2016. aspx.

18 https://www.camara.cl/pley/pley_detalle.aspx?prmID=10861.

19 http://www.cut.cl/pdf/Analisis\%20Proyecto\%20de\%20Ley\%20de\%20Reformas\%20Laborales.pdf.

20 http://www.chilevision.cl/tolerancia_cero/noticia/empresarios-critican-duramente-la-reforma-laboral-atraves-de-video/2015-04-15/150748.html. 
Por otra parte, la caída en la credibilidad y confianza hacia las empresas se profundizó por las denuncias de colusión entre empresas del sector naviero ${ }^{21}$ y papelero, ${ }^{22}$ y por el término judicial de los casos de colusión en las farmacias ${ }^{23}$ y entre los productores de pollos. ${ }^{24}$ Particular atención generó el caso papelero, conocido popularmente como la "colusión del confort" (papel higiénico). ${ }^{25}$ Este estalló cuando la Fiscalía Nacional Económica presentó una acusación contra las papeleras CMPC Tissue y SCA Chile, la cual les imputa haberse coludido para asignarse cuotas de mercado y fijar precios de venta del papel tissue entre los años 2000 y 2011. Las reacciones, tanto del mundo político como económico, no se hicieron esperar, ${ }^{26}$ coincidiendo en un amplio rechazo al accionar de las empresas.

En este contexto, Bachelet firmó en marzo un proyecto de ley que, entre otras materias, establece hasta 10 años de cárcel por colusión (Boletín 9950-03).27 Este se debate actualmente en el Parlamento y se espera contribuya a evitar en el futuro este tipo de prácticas y se sancionen adecuadamente. La Cámara de Diputados, por su parte, acordó la creación de una comisión investigadora en esta materia. ${ }^{28}$

\section{Coyuntura Internacional}

La coyuntura internacional estuvo marcada, en primer lugar, por el fallo de la Corte Internacional de Justicia (CIJ) respecto de la Excepción Preliminar planteada por Chile en el marco de la demanda presentada por Bolivia en abril de $2013 .{ }^{29}$ Una vez presentada la Memoria de Bolivia ante la Corte (abril de 2014), las autoridades chilenas discutieron si Chile debía o no impugnar la competencia de la Corte, y si esta debía ser presentada durante el período de excepciones preliminares o si debía ser abordada en la Contra Memoria Chilena. Finalmente, Bachelet anunció que para "salvaguardar el interés superior de Chile, he tomado la decisión de objetar la competencia de la Corte Internacional de La

21 http://www.emol.com/noticias/economia/2015/01/28/701288/fne-acusa-a-seis-navieras-por-colusion-entransporte-de-vehiculos-y-pide-multa-de-us-75-millones.html.

22 http://www.emol.com/noticias/Economia/2015/10/28/756586/Colusion-de-empresas-de-papel-confort. html.

23 http://www.emol.com/noticias/Nacional/2015/12/29/765957/Caso-Farmacias-Corte-confirma-fallo-queabsolvio-a-ejecutivos-acusados-de-colusion.html.

24 http://www.emol.com/noticias/Economia/2015/10/29/756762/Caso-Pollos-Suprema-ratifica-multa-deUS-60-millones-contra-empresas-culudidas.html.

25 http://www.fne.gob.cl/2015/10/28/fne-presenta-requerimiento-por-colusion-contra-cmpc-y-sca/\#more-73559.

26 http://www.emol.com/noticias/Nacional/2015/10/30/756915/Bachelet-pide-rapidez-al-Congreso-paraaprobar-aumento-de-sanciones-a-la-colusion.html.

http:/ /www.emol.com/noticias/Economia/2015/10/29/756788/Sofofa-espera-que-empresas-coludidasdefinan-como-repararan-dano-causado.html.

http://www.emol.com/noticias/Nacional/2015/10/31/757005/Camila-Vallejo-arremete-contra-Lagos-porcolusion-Fue-el-quien-elimino-la-sancion-de-carcel.html.

27 Para efecto de su tramitación legislativa, los proyectos de ley son identificados con un número de boletín. Con este número se puede acceder a toda su tramitación en la página del Congreso, www.congreso.cl.

28 http://www.emol.com/noticias/Nacional/2015/11/04/757569/Diputados-aprueban-creacion-de-comisioninvestigadora-por-colusion-de-papeleras.html.

29 La demanda presentada por Bolivia en 2013, solicitaba a la CIJ que se obligue a Chile a negociar con Bolivia un acuerdo que le otorgue acceso soberano al Océano Pacífico (Castiglioni, 2014). 
Haya, presentando para ello objeciones preliminares a la jurisdicción de dicha corte". ${ }^{30}$ En julio de 2014 se entregó la solicitud.

En septiembre de 2015, la CIJ rechazó la petición chilena declarándose competente para conocer la demanda boliviana, por 14 votos contra 2. ${ }^{31}$ Sin embargo, agregó que el objeto de la controversia era determinar si Chile debía negociar un acceso soberano de Bolivia al Pacífico y que "no le corresponde determinar el resultado de tal negociación". 32 Bachelet, se colgó de esto para dar una interpretación positiva, indicando que el fallo "no afecta en nada nuestra integridad territorial, y en ese sentido, Bolivia no ha ganado nada". ${ }^{33}$ En la vereda contraria, Evo Morales declaraba su satisfacción con el fallo, afirmando que "Bolivia nunca ha claudicado y nunca claudicará hasta volver al Pacífico con soberanía". ${ }^{34}$ Con este fallo, el juicio continúa y Chile debe presentar su Contra Memoria a la Corte en 2016.

Pese a la lectura positiva que se buscó dar al fallo por parte de Chile, las críticas al trabajo realizado por Felipe Bulnes 35 terminaron con su renuncia como agente chileno ante la CIJ.36 En su reemplazo asumió José Miguel Insulza, exsecretario general de la OEA. ${ }^{37}$

En materia de política comercial, en octubre 2015 concluyó la negociación del Trans-Pacific Partnership Agreement (TPP), tratado de integración económica que crea una zona de libre comercio entre 12 países de la cuenca del Pacífico. ${ }^{38} \mathrm{El}$ acuerdo regula distintas materias incorporando "disposiciones y disciplinas no incluidos en otros tratados comerciales, tales como: empresas del Estado, disposiciones anticorrupción, coherencia regulatoria, competencia, y, pequeñas y medianas empresas, entre otros temas". ${ }^{39}$ De acuerdo con el Ministerio de Relaciones Exteriores, este tratado es relevante porque incluye a países con los que Chile tiene un intercambio comercial significativo, representando el $30 \%$ del comercio del país durante 2015.40 El acuerdo fue firmado en Nueva Zelanda en febrero de 2016, ${ }^{41}$ pero para entrar en vigencia debe ser ratificado por el Congreso. Se espera html.

31 http://diario.latercera.com/2015/09/25/01/contenido/pais/31-198834-9-la-haya-dejara-en-manos-de-chiley-bolivia-resultado-de-eventual-negociacion.shtml.

32 http://diario.latercera.com/2015/09/25/01/contenido/pais/31-198834-9-la-haya-dejara-en-manos-de-chiley-bolivia-resultado-de-eventual-negociacion.shtml.

33 http://www.emol.com/noticias/Nacional/2015/09/24/751344/Bachelet-tras-fallo-de-La-Haya-Dejaremosen-evidencia-la-falta-de-fundamentos-de-la-demanda-boliviana.html.

34 http://www.la-razon.com/nacional/demanda_mar\%C3\%ADtima/Morales-asegura-CIJ-Chiledialogar_0_2350565001.html.

35 http://www.elmostrador.cl/noticias/pais/2015/11/23/bulnes-deja-equipo-de-defensa-ante-la-haya-molestopor-criticas-de-chile-vamos-y-entorno-de-pinera/. http://diario.latercera.com/2015/11/24/01/contenido/pais/31-203374-9-bachelet-nombra-a-insulza-en-lahaya-tras-renuncia-de-bulnes-por-falta-de.shtml.

37 http://chileantelahaya.gob.cl/jose-miguel-insulza-nuevo-agente-chileno-ante-la-corte-internacional-dejusticia-de-la-haya/.

38 http://www.direcon.gob.cl/2015/10/tras-cinco-anos-de-negociaciones-los-12-paises/.

39 http://www.direcon.gob.cl/tpp/antecedentes-generales/.

40 http://www.direcon.gob.cl/tpp/antecedentes-generales/.

41 http://www.t13.cl/noticia/negocios/tpp-chile-firma-acuerdo-transpacifico-junto-otros-11-paises. 
una intensa discusión ya que algunos actores (como parlamentarios del PC y del PS) han manifestado su rechazo.

\section{CAMBIOS INSTITUCIONALES Y CAMBIOS SUSTANTIVOS EN POLÍTICAS PÚBLICAS}

\section{Cambios Institucionales}

No obstante el difícil 2015, este fue un año clave en términos institucionales. Por un lado, distintas reformas (algunas concluidas en 2016) modificaron sustantivamente el marco de la competencia política. Estas son la reforma electoral (Ley $\mathrm{N}^{\mathrm{o}} 20.840$ ) y los nuevos marcos legales sobre financiamiento político e institucionalidad reguladora electoral, y sobre partidos políticos. Por el otro, el gobierno definió un cronograma del proceso de reforma constitucional.

\section{Reforma electoral}

Esta es una de las transformaciones institucionales más relevantes introducidas en Chile desde 1990. La Ley $N^{\circ} 20.840$ puso fin al sistema binominal vigente desde 1989 y lo sustituyó por uno "proporcional de carácter inclusivo". Los contenidos principales tanto del sistema binominal como del nuevo sistema se resumen en la Tabla 1.42

Los pilares del nuevo sistema son los siguientes. Primero, se aumentó el número de parlamentarios a elegir: de 120 a 155 en la Cámara de Diputados (CD), y de 38 a 50 en el Senado. ${ }^{43}$

Segundo, se modificaron los territorios electorales y su magnitud (número de cargos a elegir en cada uno). En el caso de la CD, se crearon 28 nuevos distritos, cuya magnitud varía entre tres y ocho. Corresponde al Servicio Electoral (SERVEL) actualizar cada 10 años (según variaciones de población) el número de diputados por distrito (siempre con mínimo de 3 y máximo de 8). En el caso del Senado, desde 2017 cada región constituirá una circunscripción senatorial, eligiendo cada una entre dos y cinco senadores. Para ambas Cámaras se mantiene la regla D’Hondt de asignación de escaños.

Tercero, los partidos o pactos entre partidos pueden incluir un número de candidatos superior en uno al número de cargos a elegir. Por ejemplo, si en un distrito se eligen siete cargos, cada lista puede incluir hasta 8 personas. Por último, y muy importante, se introdujo por primera vez en Chile una "ley de cuotas". Según esta, "ni los candidatos hombres ni las candidatas mujeres podrán superar el sesenta por ciento del total respectivo" (Ley $\mathrm{N}^{\circ} 20.840$, artículo $1^{\circ}$ ). Esta regla estará vigente para las cuatro elecciones que deben tener lugar entre 2017 y 2029. Asimismo, se establecieron transitoriamente incentivos económicos para la postulación de mujeres al Parlamento.

42 Para un análisis del sistema binominal, ver Huneeus (2006).

$43 \quad \mathrm{Al}$ ser el Senado elegido por parcialidades, desde 2017 tendrá 43 miembros y en 2021 completará los 50. 
Tabla 1. Comparación entre el sistema binominal y el proporcional moderado

\begin{tabular}{ccc}
\hline & Sistema & Nuevo Sistema \\
Materia & Binominal & Proporcional Moderado \\
& $(1989-2015)$ & (desde 2017) \\
\hline
\end{tabular}

\section{Escaños}

Cámara de Diputados $\quad 120 \quad 155$

$\begin{array}{lll}\text { Senado } & 38 & 50\end{array}$

\section{Distritos}

Cámara de Diputados $\quad 60 \quad 28$

$\begin{array}{lll}\text { Senado } & 19 & 15\end{array}$

\begin{tabular}{|c|c|c|}
\hline \multicolumn{3}{|l|}{ Magnitud del Distrito (M) } \\
\hline Cámara de Diputados & 2 & Variable entre 3 y 8 \\
\hline Senado & 2 & Variable entre 2 y 5 \\
\hline Fórmula de Asignación de Escaños & D'Hondt & D'Hondt \\
\hline Pactos & Permitido a nivel nacional & Permitido a nivel nacional \\
\hline Cuota de género & No & $\begin{array}{l}\text { Los candidatos de un pacto o } \\
\text { partido de un mismo sexo no } \\
\text { pueden superar el } 60 \% \text { del total }\end{array}$ \\
\hline Máximo de Candidatos por Lista & M & $M+1$ \\
\hline
\end{tabular}

Fuente: Leyes Nos. 18.799 y 20.840.

La reforma es un cambio sustantivo, y positivo, a las reglas de competencia política. Principalmente, porque se reducen significativamente las barreras de entrada al sistema. Por ejemplo, en los distritos que elegirán 8 diputados, una lista puede asegurar un cargo con solo $11,2 \%$ de los votos. En el caso del binominal, ello se hacía con 33,4\%. Por lo tanto, lo probable es que el próximo Congreso sea más representativo, y que se reduzca la desproporcionalidad entre votos y escaños de cada partido. Asimismo, dado que se eligen más diputados y en distritos más grandes, también aumentan los niveles de incertidumbre, lo que podría impactar en la percepción de competencia política por parte de los electores y en los niveles de participación. Igualmente, es posible que suba el porcentaje de mujeres en el Parlamento, que hoy es de 18\% en el caso de la Cámara y de 15,8\% en el del Senado. Por otra parte, dados los nuevos dibujos de los distritos, se nivela la proporción de habitantes y de escaños asignados a cada distrito, reduciendo el malapportionment en el caso de la CD (de 17,8\% a 10,6\%, calculado según el índice de Loosemory y Handby).

\section{Financiamiento de la política y Ley de Partidos}

Como reacción al escándalo de financiamiento ilegal de la política, el gobierno creó el “Consejo Asesor Presidencial contra los conflictos de interés, el tráfico de influencias y 
la corrupción", liderado por el profesor Eduardo Engel. La "Comisión Engel" emitió un informe en abril, el que contiene, entre otras cosas, propuestas de cambio en materia de organización partidaria y de financiamiento de la política. Estas sugerencias, al menos en parte, fueron incorporadas en un proyecto que modifica la ley de partidos (Boletín 10154-07) y al proyecto sobre financiamiento político que estaba en discusión desde 2014 (Boletín 9790-07). Ambos fueron objeto de fuerte controversia en 2015, no obstante terminaron su tramitación legislativa en enero de 2016.

El proyecto aprobado sobre financiamiento de la política, en lo sustantivo, hace lo siguiente. ${ }^{44}$

a) Prohíbe el aporte de personas jurídicas a campañas electorales y partidos, pudiendo solo hacerlo las personas naturales. Los límites máximos de estos aportes fueron reducidos, como también el de los aportes anónimos;

b) Establece un sistema de financiamiento público de los partidos políticos. El monto total a repartir entre los partidos es variable de acuerdo a ciertas reglas, y se distribuye así: el 20\% se hace por partes iguales entre los partidos (proporcionalmente al número de regiones en que estén inscritos), mientras el restante $80 \%$ se reparte entre los partidos con representación parlamentaria y en proporción a los votos obtenidos en la última elección de diputados. Se calcula que en 2016 el monto total a repartir sería de 8,5 millones de dólares. ${ }^{45}$ Asimismo, se dispone que si bien los partidos recibirán esos recursos en 2016, para que esto ocurra en 2017 deben realizar un proceso de reinscripción de militantes;

c) Reduce considerablemente los montos máximos de gasto en campañas;

d) Aumenta el reembolso estatal de campañas electorales;

e) Limita el espacio físico para la instalación de propaganda electoral;

f) Crea un nuevo estatuto del SERVEL, aumentando sus atribuciones para la fiscalización $\mathrm{y}$ control de los gastos y aportes electorales, $\mathrm{y}$

g) Aumenta, en general, las sanciones por incumplimiento de las normas que regulan el financiamiento de la política.

El proyecto aprobado sobre partidos políticos, en lo esencial, hace lo siguiente ${ }^{46}$ :

a) Establece que los partidos tendrán personalidad jurídica de derecho público y redefine en forma más amplia sus funciones;

b) Modifica los requisitos para formar partidos políticos y condiciones de disolución. Además de cuestiones formales, se exige la firma de $0,25 \%$ de las personas que votaron en la respectiva región en la última elección de diputados (con un mínimo de 500 por región) y que ello se haga en ocho regiones, o en tres si son geográficamente

44 https://www.camara.cl/pley/pley_detalle.aspx?prmID=10201\&prmBoletin=9790-07.

45 http://www.latercera.com/noticia/nacional/2016/01/680-666041-9-estado-destinara-este-ano--6000-millonespara-financiar-a-los-partidos-politicos.shtml.

46 https://www.camara.cl/pley/pley_detalle.aspx?prmID=10581\&prmBoletin=10154-07. 
contiguas. ${ }^{47}$ Los partidos que no alcancen el $5 \%$ de los votos en la última elección de diputados (en las regiones en que esté constituido) serán disueltos, a menos que obtengan cuatro parlamentarios en al menos dos regiones distintas;

c) Incorpora un catálogo de derechos y deberes de los militantes, que todo estatuto partidario debe respetar. En particular, garantiza derechos de participación y acceso a información, como también el acudir a entes externos (TRICEL) para impugnar decisiones de órganos partidarios internos;

d) Introduce nuevas reglas sobre organización interna de los partidos. Los miembros de sus órganos principales deben elegirse democráticamente, determinando cada partido el sistema electoral a utilizar, el que en todo caso debe observar el carácter personal, igualitario, libre, secreto e informado del voto;

e) Establece reglas para la administración de los bienes de los partidos y sus finanzas;

f) Crea nuevas obligaciones para los partidos en materia de información que debe mantener al público y normas para exigir su cumplimiento.

Conjuntamente, se promulgó una reforma constitucional (Ley $\mathrm{N}^{\circ}$ 20.870) que establece la cesación en los cargos de parlamentario, alcalde, consejero regional y concejal, por infracción grave a las normas sobre gasto electoral.

\section{El proceso constituyente}

Una propuesta central de Bachelet era generar una nueva Constitución, que establezca nuevas bases del sistema político y en la relación Estado-Sociedad. Esta aspiración tan sustantiva fue presentada como una de las tres "Reformas de Fondo" a desarrollar en su gobierno, a partir del diagnóstico de que existe una "demanda nacional por una Nueva Constitución Política para Chile a impulsar en un proceso democrático, institucional y participativo que permita alcanzar este propósito" (Bachelet, 2013:30). No obstante, no contenía ninguna definición sobre qué procedimiento se utilizaría.

El gobierno dilató largamente su decisión al respecto, desatando críticas de distintos actores, tanto impulsores, ${ }^{48}$ como detractores de la idea de una nueva constitución. ${ }^{49}$ Finalmente, en octubre Bachelet anunció el cronograma del proceso constituyente. Este distingue las siguientes etapas: ${ }^{50}$

a) Hasta marzo de 2016 se desarrollaría una etapa de "educación cívica y constitucional", con el objeto de que los chilenos se informen de lo que significa el proceso;

b) En marzo de 2016 se iniciaría un "proceso ordenado de diálogos ciudadanos", los que tendrán lugar a nivel comunal, provincial y regional y terminarían en una "síntesis a nivel nacional". El resultado de estos diálogos serán las "Bases Ciudadanas para

47 En la Ley $\mathrm{N}^{\mathrm{o}} 20.840$ se había establecido como requisito el 0,25\% (sin mínimo) y solo en una región.

48 http://radio.uchile.cl/2015/05/23/movimiento-por-la-ac-critica-ambiguedad-del-gobierno-para-definirmecanismo-para-nueva-constitucion.

49 http://www.emol.com/noticias/nacional/2014/12/02/692796/presidente-de-la-udi-y-anuncio-de-nuevaconstitucion.html.

50 http://www.gob.cl/2015/10/13/discurso-de-la-presidenta-de-la-republica-al-anunciar-el-proceso-constituyente/. 
la Nueva Constitución", que se entregarán a Bachelet en octubre de 2016. Para asegurar que la participación ciudadana sea "libre, transparente, sin distorsiones ni presiones de ningún tipo", se nombraría un Consejo Ciudadano de Observadores, cuya misión sería acompañar el proceso y dar garantías de transparencia y equidad.

c) El segundo semestre de 2017 el gobierno presentaría al Congreso su proyecto de nueva Constitución. Previo a eso, a fines de 2016, se enviaría un proyecto de reforma de la actual Constitución para que el Congreso, por 2/3 de sus miembros, "establezca los procedimientos que hagan posible dictar una nueva Carta Fundamental". De esta manera, entonces, el actual Congreso definiría cuatro alternativas para reformar la Constitución: i) crear una Comisión Bicameral de Senadores y Diputados; ii) formar una Convención Constituyente mixta de parlamentarios y ciudadanos; iii) convocar a una Asamblea Constituyente, y; iv) que se convoque a plebiscito, para que la ciudadanía decida entre estas anteriores alternativas. Hecho esto, el Congreso que se elija en 2017 determinará (con quórum de 3/5 de sus miembros) qué procedimiento utilizar, de entre estas cuatro alternativas. La instancia que se elija es la que deberá discutir el proyecto que enviará Bachelet. Sancionado por ella, el proyecto que emita debe ser sometido a ratificación vía plebiscito.

En los últimos meses de 2015 se comenzó a implementar el anuncio. Por un lado, aunque sin mucha intensidad, se desplegó una campaña publicitaria de información, cuyo eje central son videos educativos sobre la reforma constitucional. ${ }^{51}$ Por el otro, se creó el Consejo Ciudadano de Observadores, integrado por 15 personas, de distintas orientaciones políticas y provenientes de diversos sectores de la sociedad. ${ }^{52}$ En este momento (enero de 2016), se discute la forma concreta de los mecanismos de participación ciudadana.

\section{Cambios en Políticas Públicas}

Desde el punto de vista de las políticas públicas, durante 2015 se aprobaron leyes que modificaron aspectos esenciales concernientes a las áreas de derechos civiles, salud y educación.

Una decisión relevante fue la sanción de la Ley N² 20.830 -el Acuerdo de Unión Civil (AUC) - que regula la convivencia entre personas que comparten un hogar (ya sean homosexuales o heterosexuales) y que, cumpliendo ciertos requisitos, pasan a ser considerados parientes legalmente. La ley regula, además, diversos aspectos relacionados con los derechos y deberes de los convivientes, como las cuestiones patrimoniales (herencias, beneficios sociales de uno y otro). ${ }^{53}$ Esto, indudablemente, representa un gran avance en el reconocimiento de derechos de las personas.

En materia de salud, en junio fue promulgada la Ley "Ricarte Soto", en alusión a un periodista fallecido el 2013 y que había impulsado mejoras al acceso a financiamiento de enfermedades de alto costo (Ley $\mathrm{N}^{\circ}$ 20.850). La ley establece un sistema de protección

\footnotetext{
51 http://www.constitucionario.cl/\#mira.

52 http://www.gob.cl/2015/12/02/presidenta-nombra-a-integrantes-del-consejo-ciudadano-de-observadores/.

53 http://www.leychile.cl/Navegar?idNorma=1075210.
} 
financiera para el diagnóstico y el tratamiento de estas enfermedades (p.e. esclerosis múltiple refractaria o cáncer de mamas), pasando a ser parte de las garantías de salud. Con esto, los beneficiarios del sector público y privado de la salud estarán cubiertos en el diagnóstico y tratamiento de 11 patologías. ${ }^{54}$

También hubo un avance fundamental en materia educativa: la reforma que establece la gratuidad de la educación universitaria para un amplio grupo de personas (Ley $\mathrm{N}^{\circ}$ 20.890). ${ }^{55}$ De acuerdo a esta, tienen derecho a este beneficio quienes pertenezcan al $50 \%$ más vulnerable de la población y sean admitidos en alguna de las universidades que cumplen ciertos requisitos (p.e. 4 años de acreditación mínimo y que no tengan fines de lucro). ${ }^{56}$ Se calcula que en 2016 podrían acceder a la gratuidad cerca de 160 mil personas. Con todo, cabe precisar dos cosas: a) este beneficio no se estableció por medio de una ley permanente, sino a través de la ley de presupuestos, la cual tiene validez solo por un año; b) esta ley es una modificación a la norma originalmente aprobada, la que fue declarada por el Tribunal Constitucional como discriminatoria e inconstitucional.

A lo anterior se suman la promulgación de las siguientes leyes: a) $\mathrm{N}^{\circ} 20.800$, que establece normas para la administración de instituciones de educación superior; b) $\mathrm{N}^{\circ} 20.845$ que modifica las normas sobre financiamiento educacional y prohibición del lucro, y c) $\mathrm{N}^{\circ} 20.842$ que creó las universidades estatales de la Región de O'Higgins y de la Región de Aysén. ${ }^{57}$

Pese a esto, se necesitan avances mayores. De hecho, en materia de reforma educacional faltan leyes relevantes (p.e. las que se refieren a la desmunicipalización y a la educación superior), además que debe establecerse el sistema de gratuidad universitaria mediante una ley permanente. Por otra parte, en otras áreas se evidencia un fuerte déficit, como en salud, en particular en infraestructura hospitalaria. 58

\section{PODER EJECUTIVO}

Durante 2015 hubo 3 cambios de gabinete. El gabinete original de Bachelet fue presentado en enero de 2014 (ver Tabla 2). De los 23 ministros, 14 (61\%) son hombres y 9 (39\%) mujeres. Respecto de la composición política, el PPD contó con más ministros, $6(26 \%)$, seguido por el PDC y el PS, cada uno con 5 ministros (22\%), el PRSD con $2(9 \%)$, la Izquierda Ciudadana, el MAS y el PC con un ministro cada uno y dos independientes.

Los cambios de gabinete de 2015 se muestran en la Tabla 3. Estos respondieron a distintas causas y tuvieron una magnitud (en términos de la cantidad de ministros salientes) también variada. El primero se realizó el 23 de enero, cuando Carmen Castillo fue nombrada ministra de Salud, en reemplazo de Helia Molina, que había renunciado en diciembre de 2014.

\footnotetext{
54 http://www.leychile.cl/Navegar?idNorma=1078148.

55 http://www.leychile.cl/Navegar?idNorma=1085782.

56 http://www.emol.com/noticias/Nacional/2016/01/11/767872/Bachelet-sobre-beneficiados-con-gratuidadEsto-no-es-un-regalo-es-un-derecho.html.

57 http://www.bcn.cl/historiadelaley/nc/historia-de-la-ley/4059/.

58 http:/ / radio.uchile.cl/2015/11/11/nueva-renuncia-en-minsal-agrava-crisis-en-sector-salud.
} 


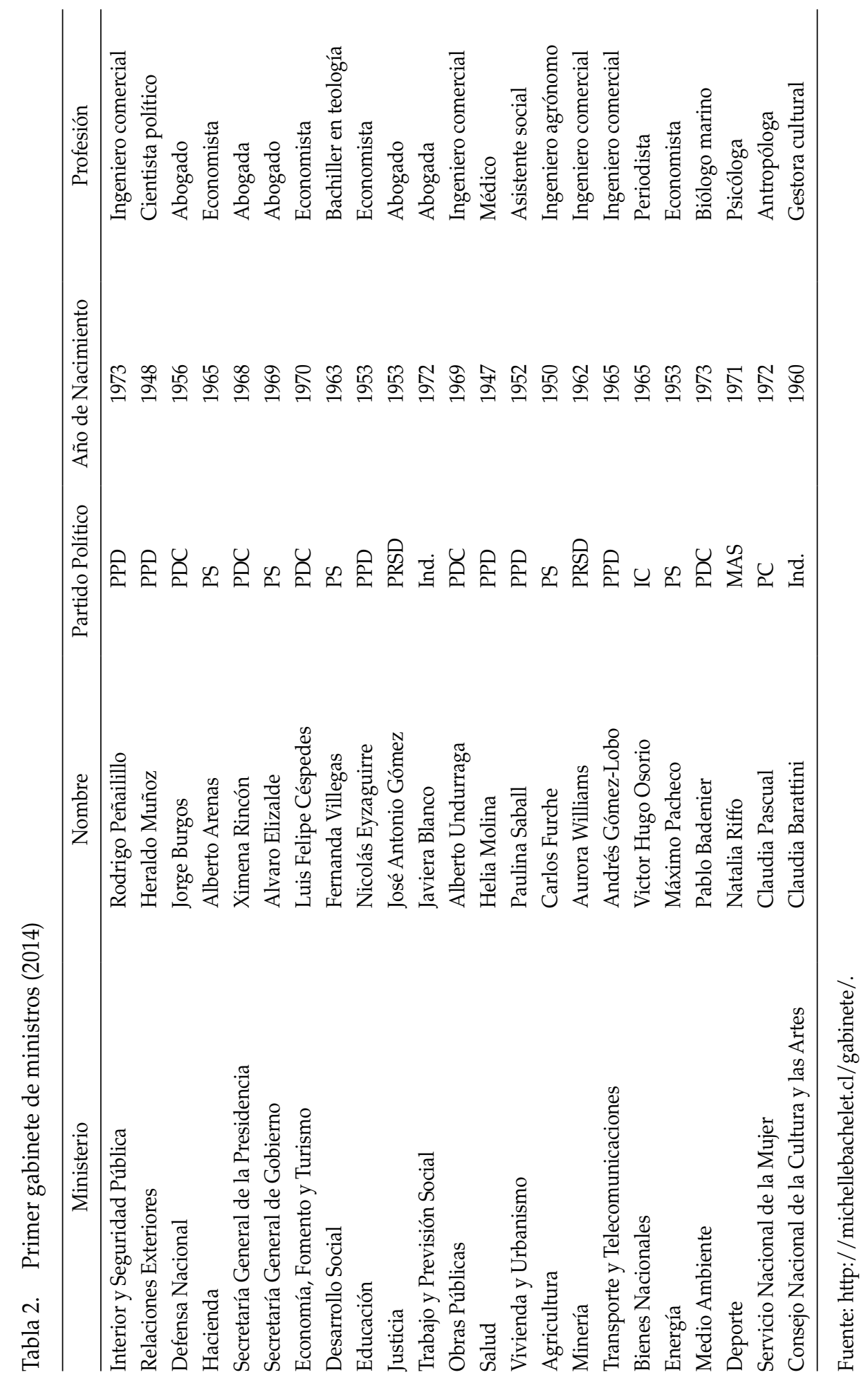




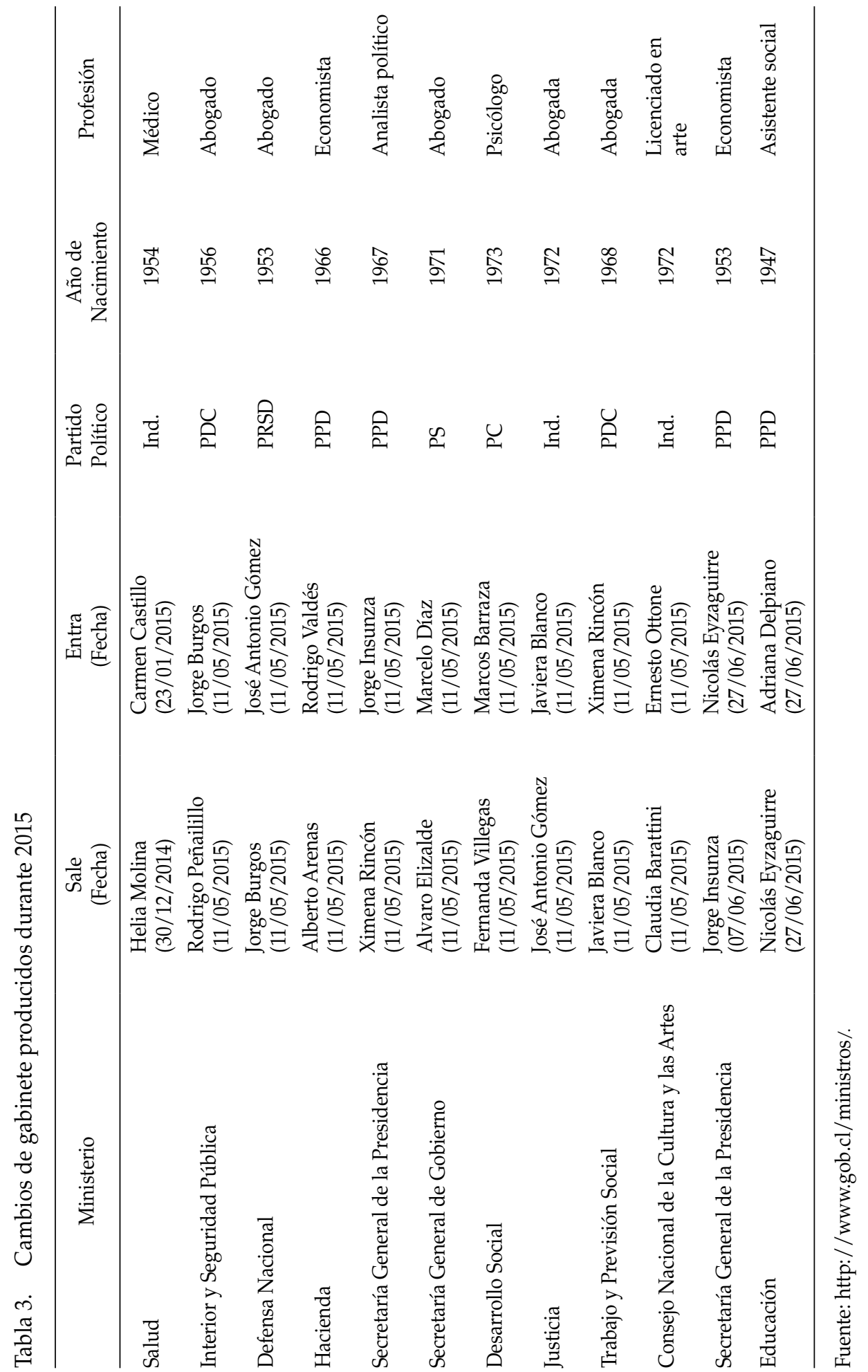


El segundo cambio de gabinete, realizado el 11 de mayo, fue el más importante, tanto por su significado político como por su magnitud. En esa oportunidad, 9 ministros fueron removidos, incluyendo a los tres ministros más cercanos -política y personalmentea Bachelet (Peñailillo, Arenas y Elizalde). Igualmente, 4 de los 9 ministros removidos asumieron otros ministerios (Burgos a Interior, Rincón a Trabajo, Gómez a Defensa, y Blanco a Justicia). Con esto, el equipo político completo fue modificado.

Por último, el nombrado ministro de la SEGPRES, Jorge Insunza, duró apenas 27 días en su cargo, luego que fuera fuertemente cuestionado por haber realizado asesorías a distintas empresas mineras..$^{59}$ Fue reemplazado en junio por Nicolás Eyzaguirre, y en Educación asumió Adriana Delpiano. ${ }^{60}$

\section{PODER LEGISLATIVO}

La elección parlamentaria de 2013 configuró un parlamento, en que la NM obtuvo la mayoría en ambas Cámaras (Tabla 4). Como dijimos, esto hacía prever que la coalición avanzaría rápido con sus principales reformas. Sin embargo, debido a diversos factores el trabajo de coordinación entre gobierno y mayoría parlamentaria no ha sido lo fluido que se esperaba.

Tabla 4. Conformación de la Cámara de Diputados y del Senado (2014-2018)

\begin{tabular}{|c|c|c|c|c|}
\hline \multirow{2}{*}{ Partido } & \multicolumn{2}{|c|}{ Cámara de Diputados } & \multicolumn{2}{|c|}{ Senado } \\
\hline & $\mathrm{N}$ & $\%$ & $\mathrm{~N}$ & $\%$ \\
\hline Partido Demócrata Cristiano (PDC) & 21 & 17,5 & 7 & 18,4 \\
\hline Partido por la Democracia (PPD) & 15 & 12,5 & 6 & 15,8 \\
\hline Partido Radical Social Demócrata (PRSD) & 6 & 5,0 & - & \\
\hline Partido Socialista (PS) & 16 & 13,3 & 6 & 15,8 \\
\hline Partido Comunista (PC) & 6 & 5,0 & - & \\
\hline Partido Movimiento Amplio Social (MAS) & - & - & 1 & 2,6 \\
\hline Partido Liberal de Chile (PL) & 1 & 0,8 & - & \\
\hline Independientes & 11 & 9,2 & 4 & 10,5 \\
\hline Renovación Nacional (RN) & 15 & 12,5 & 6 & 15,8 \\
\hline Unión Demócrata Independiente (UDI) & 29 & 24,2 & 8 & 21,1 \\
\hline Total & 120 & 100 & 38 & 100 \\
\hline
\end{tabular}

Fuente: www.senado.cl y www.camara.cl.

59 http://www.elmostrador.cl/noticias/pais/2015/06/04/empresa-familiar-de-ministro-insunza-recibio-pagospor-mas-de-us-300-mil-de-codelco/.

60 http://www.emol.com/noticias/Nacional/2015/06/27/723459/Nueva-titular-de-Educacion-exhibe-ampliaexperiencia-en-el-area-y-en-cargos-de-gobierno.html. 
Aun así, sin embargo, no se ha producido una parálisis legislativa ni mucho menos. Como lo muestra la Tabla 5, el número de presentación de mensajes y mociones incluso creció comparado con el año 2014. A la vez, se bien se publicaron un número menor de leyes, el número de 2015 es solo levemente menor.

Tabla 5. Estadísticas de la labor legislativa (2014-2015)

\begin{tabular}{lrrrrr}
\hline & \multicolumn{2}{c}{2014} & & \multicolumn{2}{c}{2015} \\
\cline { 2 - 3 } \cline { 5 - 6 } & $\mathrm{N}$ & $\%$ & & $\mathrm{~N}$ & $\%$ \\
\hline Proyectos Ingresados & & & & 531 & 83,1 \\
Moción & 442 & 82,8 & & 108 & 16,9 \\
Mensaje & 92 & 17,2 & & 531 & 100,0 \\
\hline Total & 534 & 100,0 & & 42 & 38,5 \\
\hline Leyes Publicadas & 41 & 36,0 & & 67 & 61,5 \\
Moción & 73 & 64,0 & & 109 & 100,0 \\
Mensaje & 114 & 100,0 & & & \\
\hline Total & & & & & \\
\hline
\end{tabular}

Fuente: Cámara de Diputados, Boletín Estadístico 2014 y 2015.

\section{RELACIÓN ENTRE LOS PODERES DEL ESTADO}

Las dificultades políticas de 2015 no tuvieron como eje, al menos principal, conflictos salientes entre poderes del Estado. Por un lado, como vimos, legislativamente fue un año de producción "normal". A este respecto, las únicas diferencias sustantivas ocurrieron en el caso de la reforma a la gratuidad (ley de presupuestos), en donde la oposición hizo caer la fórmula aprobada originalmente a través de reclamar su inconstitucionalidad ante el Tribunal Constitucional. Lo mismo intentó en el caso de la reforma electoral, pero su reclamo fue rechazado. Fuera de lo propiamente legislativo, el conflicto más relevante se vivió con ocasión de la proposición, por parte del gobierno, de Enrique Rajevic como Contralor General de la República. Esto después que el cargo estuviera vacante por seis meses. Esta propuesta no prosperó (se necesitaban 2/3 para la aprobación, 22 senadores), debido al cerrado rechazo de los partidos de oposición, que cuestionaron la integridad del candidato y su independencia política. ${ }^{61}$ En diciembre el Senado aprobó a Jorge Bermúdez como Contralor. ${ }^{62}$

61 http://www.24horas.cl/politica/senado-rechaza-nominacion-de-enrique-rajevic-como-nuevo-contralor--1814944.

62 http://www.latercera.com/noticia/politica/2015/12/674-660334-9-senado-aprueba-designacion-de-jorgebermudez-como-nuevo-contralor.shtml. 
En cuanto a las relaciones entre Ejecutivo y Poder Judicial, salvo la expresión de desacuerdos por parte de la Corte Suprema respecto de algunos contenido del proyecto de "ley corta antidelincuencia" del gobierno, ${ }^{63}$ no hubo conflictos mayores.

Por último, cabe mencionar que la elección del nuevo jefe del Ministerio Público sucedió sin mayores contratiempos. Esta, sin duda, era una decisión difícil, ya que se trataba de elegir a quien debía conducir las investigaciones sobre financiamiento ilegal de la política. No obstante Bachelet no propuso a quienes, según la prensa, podían ser los "favoritos" de los políticos, el Senado aprobó con amplia mayoría a Jorge Abbott como Fiscal Nacional. ${ }^{64}$

\section{CALIDAD DE LA DEMOCRACIA Y PERSPECTIVAS PARA 2016}

El 2015 se hizo muy evidente el problema de la relación entre política y dinero en el sistema político. A consecuencia de esto, este fue el año de mayor debilidad del sistema político desde el punto de vista de la confianza pública hacia las principales instituciones y líderes. A esto se sumó que los principales "resortes" del sistema político mostraron fuertes debilidades en el ejercicio de sus funciones, lo que se expresó en la disminuida capacidad de conducción política del gobierno y los partidos de la NM. Los partidos de oposición tampoco cumplieron su rol debidamente. De esta manera, como dice el título, el sistema político presenta hoy una "falla" profunda de funcionamiento, mientras los ciudadanos desconfían fuertemente de sus principales actores.

No obstante, hay elementos a rescatar. Primero, el funcionamiento de los controles horizontales del sistema, en términos de que la Justicia ha podido llevar adelante su trabajo sin ser obstaculizada por otros poderes del Estado. Segundo, se mostró cierta capacidad de reacción, ya que las reformas institucionales apuntan en el sentido correcto, mejorando las condiciones para una mayor y mejor competencia política.

Esto plantea un 2016 que puede ser aún más complejo que 2015. Esto, porque no solo no se avizora un cambio mayor en la capacidad de conducción política (de los actores relevantes), sino también porque el escenario económico es negativo (lo que impone restricciones a la agenda de reformas). Se suma el que este es un año electoral (elecciones municipales en octubre) donde las demandas sociales de exacerban, y eventualmente los conflictos gobierno-oposición e intracoaliciones aumentan. De otro lado, existe la posibilidad de una caída aún mayor en la participación electoral (solo 42\% en la segunda vuelta de 2013). Luego de ello, además, lo previsible es que se "desate" la carrera presidencial para 2017. Asimismo, aún no se sabe cuál será el desenlace de los casos judiciales de corrupción política aún en desarrollo.

Esto, sin duda, impone un desafío mayor para el sistema político. Es urgente que se reaccione con mayor fuerza y capacidad de acción colectiva, para así reconstituir una

63 http://www.elmostrador.cl/noticias/pais/2015/09/22/corte-suprema-cuestiona-duramente-ley-cortaantidelincuencia-y-califica-de-inaceptable-para-el-estado-democratico-el-control-de-identidad/.

64 http://radio.uchile.cl/2015/10/21/eleccion-de-fiscal-nacional-udi-rn-ppd-y-dc-entregan-su-apoyo. 
democracia sana, que sea de mayor calidad y sea capaz de dar adecuada respuesta a los problemas que enfrenta. Solucionar la "falla" es posible aún, pero exige mucho más que lo hecho hasta ahora.

\section{REFERENCIAS}

Adimark. 2015. Encuesta Evaluación Gestión del Gobierno. Diciembre 2015. En: http:/ /www.adimark. $\mathrm{cl} / \mathrm{es} /$ estudios/dinamica.asp?id=324.

Bachelet, Michelle. 2013. Chile de Todos. Programa de Gobierno Michelle Bachelet 2014-2018. En: http:// michellebachelet.cl/programa.

Castiglioni, Rossana. 2014. "Chile: Elecciones, Conflictos e Incertidumbre". Revista de Ciencia Política 34 (1): 79-104.

Centro de Estudios Públicos. 2015. Estudio Nacional de Opinión. Varios números. En: http:/ / www.cepchile. cl/dms/lang_1/cat_443_inicio.html.

Corbo, Vittorio. 2016. El Momento Económico Internacional y Nacional. Enero 2016. Centro de Estudios Públicos, Puntos de Referencia No 423. Enero de 2016. En: http://www.cepchile.cl/dms/ archivo_6204_3814/pder423_VCorbo.pdf.

Huneeus, Carlos (compilador). 2006. La reforma al sistema binominal en Chile. Una contribución al debate. Santiago: KAS.

Instituto Nacional de Estadísticas (INE). 2016a. Índice de Precios al Consumidor. Edición No 206. En: http:/ /www.ine.cl/boletines/detalle.php?id=1\&lang=.

. 2016b. Empleo Trimestral. Edición N 207. En: http:/ / www.ine.cl/boletines/detalle.php?id=2\&lang=.

Segovia, Carolina y Ricardo Gamboa. 2012. "Chile: El Año en que Salimos a la Calle". Revista de Ciencia Política 32 (1): 65-85.

Ricardo Gamboa es abogado de la P. Universidad Católica de Chile y doctor en Ciencia Política de la Universidad de Tübingen. Profesor asociado del Instituto de Estudios Internacionales de la Universidad de Chile. E-mail: rgamboa@uchile.cl.

Carolina Segovia es socióloga de la P. Universidad Católica de Chile y doctora en Ciencia Política de la Universidad de Michigan. Profesora asociada de la Escuela de Ciencia Política de la Universidad Diego Portales. E-mail: carolina.segovia@udp.cl. 